Original title / titulo original: Los indígenas andinos peruanos y su camino desde la marginalización clasista hasta el activismo étnico

Author(s)/ autor(es):

\title{
Aleksander Posern-Zieliński
}

Published originally as/ Publicado originalmente en: Estudios Latinoamericanos, 27 (2007), pp. 5-36.

DOI: https://doi.org/10.36447/Estudios2007.v27.art1

Estudios Latinoamericanos is a journal published by the Polish Society for Latin American Studies (Polskie Towarzystwo Studiów Latynoamerykanistycznych).

The Polish Society for Latin American Studies is scholarly organization established to facilitate research on Latin America and to encourage and promote scientific and cultural cooperation between Poland and Latin America.

Estudios Latinoamericanos, revista publicada por la Sociedad Polaca de Estudios Latinoamericanos (Polskie Towarzystwo Studiów Latynoamerykanistycznych).

Sociedad Polaca de Estudios Latinoamericanos es una asociación científica fundada con el fin de desarrollar investigaciones científicas sobre América Latina y participar en la cooperación científica y cultural entre las sociedades de Polonia y América Latina. 
Estudios Latinoamericanos 27 (2007)

Polonia

\title{
Los indígenas andinos peruanos y su camino
}

\section{desde la marginalización clasista hasta el activismo étnico}

\author{
Aleksander Posern-Zieliński
}

\section{Observaciones preliminares}

Por lo menos desde los años 90 del siglo XX, es observada en los países andinos una gran actividad étnica y política de la población nativa. Este fenómeno se manifiesta, entre otros, por el dinamismo y el alcance cada vez más visibles de diferentes organizaciones indígenas - desde el nivel local (de un pueblito o una comunidad) a través del regional, nacional, internacional, hasta el continental. Con este fenómeno está vinculado directamente el otro: la formación de un nuevo equipo de líderes indígenas, personas preparadas cada vez mejor, que disponen de una gran experiencia tanto en la actividad social-organizativa como en las negociaciones con los representantes de las autoridades estatales. Gracias a estas capacidades saben perfectamente formular los postulados con la meta de mejorar la suerte de sus "hermanos" étnicos y luchar siempre más eficazmente por alcanzarla. De esta manera, poco a poco, se esta formando un grupo de activistas políticos indígenas que comienzan a darles a los movimientos étnicos anteriores una forma de partidos, de clara orientación, exigiendo cada vez más puestos responsables en la administración nacional, tanto en el sector del poder ejecutivo, como legislativo. Todo ello hizo que en la escena política de los países andinos apareció un nuevo actor 
importante: las organizaciones indígenas. Son no solamente una fuerza social que hay que tener en cuenta durante las elecciones locales o nacionales, sino también un elemento fijo del juego político, que manifiesta su voluntad de querer influir en los principales centros de poder y participar activamente en el mismo [Posern-Zieliński 2005].

Estos fenómenos, llamados a menudo activismo indígena, aparecieron con una gran fuerza en el Ecuador y Bolivia, pero también en Chile, Colombia y Argentina, aunque en estos últimos países a menor escala debido al número de población indígena más pequeño. Hasta hace poco, sorprendía en este fondo una muy débil actividad de los movimientos etno-sociales en el Perú. La ausencia de los indígenas en la escena política peruana atraía la atención de los investigadores desde hacía varios decenios de años y provocaba a los analistas (antropólogos y sociólogos incluidos) a tratar de explicar esta anomalía "extraña".

Durante las investigaciones que estuve llevando en el Perú aún en los años 1990, también a mí me preocupaba este problema, tanto más que al mismo tiempo tenía la oportunidad de observar las transformaciones muy fuertes de las formas de actividad indígena en el Ecuador y Bolivia. Ya en aquel entonces, en estos dos países, los movimientos indígenas influían de manera significante en los resultados de las elecciones locales y parlamentarias, provocaban crisis agudas a escala nacional, traían cambios de los equipos gobernantes y ampliaban eficazmente su influencia en el curso de varios asuntos importantes, donde también en la forma de la legislación.

Es una situación interesante desde el punto de vista histórico, ya que en el pasado, tanto en la época del imperio inca de Tawantinsuyu, como también en el período colonial español de Virreinato del Perú, los terrenos actuales del Ecuador y de Bolivia eran provincias lejanas. Hoy en día pareciera que la situación es totalmente contraria. Es porque la población indígena de las antiguas periferias de la zona mencionada tomó iniciativa, demostrando un alto nivel de organización y consciencia socio-étnica, mientras que la población indígena del centro andino "cayó en un letargo difícil de entender. Mis colegas peruanos, durante las conversaciones que tuve con ellos sobre estos temas, me decían que las condiciones sociales e históricas, en cuanto a la situación de los indígenas en el Perú, diferían muchisimo de las que caracterizaban las zonas periféricas. Subrayaban que la población indigena de la parte central de los Andes (entonces del Perú) no necesitaba buscar sentimientos étnicos, porque el nivel de su integración con la principal corriente nacional era y sigue siendo bastante 
alto. Esto tenía que resultar de un gran adelanto en los procesos de formación de la unida nación peruana dividida, a lo sumo, entre conjuntos etnográfico-folclorísticos y regionales que, aunque manifestando su apego a la tradición andina, se identificaban enteramente con la nación peruana.

Tomaba esas explicaciones con comprensión, aunque con una gran dosis de escepticismo. Suponía en cierto sentido que aquel "adormecimiento" de actividad de los indigenas peruanos tuviera que resultar más de la especificidad de la historia reciente de este país (fuertes corrientes izquierdistas, política de negación de la presencia indígena en la principal corriente social del país, la guerra civil o el régimen autoritario del presidente Fujimori), que del nivel de integración de ese segmento/capa/ categoría de población. Consideraba además muy probable que en un momento dado, en los círculos de la población de origen indígena, apareciera el discurso étnico seguido de nuevas formas de organizaciones indígenas, igual que había sucedido en los países vecinos. Es que ésta ha sido la tendencia dominante entre los pueblos nativos del mundo entero y no cabe duda que los ejemplos de eficacia de los movimientos indígenas de otros paises sud y centroamericanos, como también norteamericanos, no podían quedar sin ningún eco por un tiempo infinito. Fue también por esta razón que estuve siguiendo muy cuidadosamente el desarrollo de la situación en el Perú, observando hasta los más mínimos síntomas de cambio en el ambiente nativo!.

Una de las evidentes fuentes de este proceso de desetnización fue la influencia de las corrientes políticas izquierdistas que tenian por su precursor a J. C. Mariátegui (1895-1930) quien en la primera mitad del siglo $\mathrm{XX}$ formuló la tesis de que el problema indígena en el Perú era solamente la falta de tierras, es decir el problema de la marginalización económica de los campesinos, entonces eliminarlo -como resultado de la reforma agraria- crearía premisas que permitirían a los campesinos integrarse plenamente a la corriente principal de la sociedad. El otro factor eran las

\footnotetext{
' Estos estudios fueron realizados en el marco de las fundaciones, primero del Comité de Investigaciones Científicas y luego del Ministerio de Ciencia y Educación Superior polacos. El primero de ellos (1996-1998), fue titulado "El nacimiento de una nueva identidad étnica. La modernización y el pluralismo cultural en los Andes ecuatorianos". El segundo (1999-2002) se concentraba en tres paises andinos y llevaba el título: "Las direcciones de etnodesarrollo en los países andinos. Estudio antropológico comparativo: Ecuador - Perú - Bolivia". El último (2004-2007), es titulado "Política, estrategia y retórica de la etnicidad en la época de globalización. Estudio de transformación de las sociedades y culturas andinas".
} 
regulaciones del derecho nacional, en consecuencia de las cuales la noción de "comunidad indígena" ha sido rebautizada con el término de "comunidad campesina", mientras que los "comuneros indígenas" han sido transformados oficialmente en "comuneros campesinos", es decir campesinos que vivían en comunidades. Como resultado de estos cambios, del mapa del Perú desaparecieron en un abrir y cerrar los ojos millones de indígenas andinos a quienes se comenzó de percibir sólo a través del prisma de su posición clasista o a través de "su ubicación rural, estado legal y actividad profesional Si tomar en cuenta el hecho de que los indígenas mismos -poco tiempo atrás nombrados con el término despectivo de "indios", y luego con el ya menos controvertido, pero decididamente paternalista "indigenas"- percibían su posición social como marginalizadora y excluyente de la sociedad nacional, y la que además les estigmatizaba étnicamente, no puede sorprender que rápido admitieron (sobre todo en el norte y centro del Perú) la terminología impuesta desde arriba que "ocultaba" la poco cómoda etnicidad. Como "campesinos" se sintieron por primera vez más ciudadanos y más apreciados. Comenzaron a percibirse a sí mismos en las categorías estatales-nacionales, es decir como campesinos peruanos, aunque siempre muy pobres y desamparados, pero -por lo menos potencialmente- formando parte de la principal corriente de la sociedad-nación-estado.

Un ejemplo que ilustra muy bien este cambio de consciencia, pueden ser los campesinos de la comunidad Huacho sin Pescado donde llevé mi investigación en el marco de la Expedición Científica Polaca a los Andes, todavía en el año 1978. En aquel entonces, no renunciaban a su etnicidad nativa, comúnmente utilizaban el idioma quechua y a menudo hacían referencia a la mitologizada tradición inca que percibían como una herencia importante de sus antepasados [Posern-Zieliński 1985]. Actualmente, esa misma gente, construye su identidad de manera totalmente distinta, debido a su profunda desetnización acompañada de una significante desaparición del idioma nativo, un fenómeno que va progresando cada vez más. Categóricamente rechazan sus raíces indígenas, pidiéndo al antropólogo que por favor, en sus próximas publicaciones no llame su aldea "comunidad indígena" ni a ellos mismos "indígenas".

El proceso de desindianización -tanto su "objetivo" que consistía en la deculturación y asimilación, como aquel que ocurría a nivel de la semántica del discurso- se desarrollaba sobre todo en el territorio aborigen, en los Andes y en las comunidades campesinas de la zona. La eliminación 
de la etnicidad indígena y la peruanización acelerada de los habitantes de la zonas rurales estaban acompañadas también por la interpretación mestiza del patrimonio indigena que consistía en incluir elementos de esta tradición en la cultura "nacional". De esta manera, la cultura nativa étnica se transformó en el folclore regional, mientras que el idioma quechua llegó a ser algo como un dialecto campesino, caracteristico de los peruanos que vivían en las provincias del país [Wood 2005: 11-25].

El factor importante que debilitaba la voluntad de mantener su identidad entre la población indígena, fueron los prejuicios profundamente arraigados en la sociedad mestizo-criolla para con los "indígenas", muchas veces impregnados de una encubierta actitud rascista. Resultaba que combinando la baja posición social de este grupo de población con la estigmatización étnica y clasista, entre personas que tenían algunas ambiciones y posibilidades de ascenso (p.ej. gracias a la educación, migración a la ciudad, o adquiriendo una profesión no agrícola), la etnicidad era casi siempre ocultada y luego abandonada a favor de un nuevo tipo de identidad regional-nacional. En el Perú, con una tal identidad, a pesar de la apariencia y origen evidentemente indígenas, era posible ir ascendiendo poco a poco en la escala social. La mejor prueba es ahí el ex-presidente del país, Alejandro Toledo, por su origen llamado cholo (indigena de origen campesino, pero que ya vivía en la ciudad). Dichos mecanismos hicieron que contrariamente a la situación conocida en los países limítrofes -Ecuador y Bolivia- en el Perú durante largo tiempo no había condiciones para que pudieran formarse las élites indígenas, indispensables para la creación de un movimiento indígena organizado. Los que abandonaban su comunidad de origen, comenzaban una nueva etapa de vida, adquiriendo una mejor orientación en el mundo constituido por los mestizos. Por ende, muy rápido se identificaban con él y agrandaban el segmento mestizo de la nación política del Perú. De esta manera, la sociedad indígena estaba sistemáticamente desprovista de sus representantes más activos, más emprendedores, más inteligentes y educados, quienes en otras condiciones hubieran podido no solamente convertirse en el germen de una élite indígena interesada en participar en la vida organizacional, autónoma o política, sino también sentar las bases de una clase media nativa, compuesta de especialistas, sacerdotes, maestros y pequeños empresarios.

En el caso peruano, otro factor desfavorable para los procesos de renacimiento indígena, es su estructura geopolítica interna específica. Se trata de que desde los tiempos de la colonia, los principales centros del 
poder, administrativos y económicos se encontraban en la zona de la costa del Pacífico que había sido desindianizada como primera y como primera se ha vuelto la región de asentamiento de la población criollo-mestiza. Las partes habitadas por los grupos indígenas corresponden ante todo a las regiones montañosas y de difícil acceso, situadas en el interior del país, incrustadas entre la selva amazónica y las poco pobladas regiones semi-desérticas premontanas de la Cordillera Occidental. Esa estructura de asentamientos contrastaba con el modelo incaico que situaba los centros del poder en la partes altas de los fértiles valles de la sierra. Un ejemplo de ello fue la antigua capital del Tawantinsuyu -Cusco- hoy en día ciudad conocida en el mundo entero gracias a sus valores turísticos, pero la que en el Perú tiene el estatus de un centro urbano provincial.

En Bolivia o en el Ecuador, la situación era muy distinta. Los centros capitalinos de estos dos países - La Paz y Quito- que por naturaleza de las cosas concentraban el poder y los intereses, y que daban el tono al desarrollo, están situadas en la sierra, en las regiones de alta densidad de población indígena. Esta cercanía geográfica y al mismo tiempo étnica, tenía una gran importancia, porque permitía a los grupos nativos participar en diferentes formas de protesta, mientras que a los habitantes indígenas de ambas capitales les permitía mantener fuertes lazos de solidaridad con sus propias áreas étnicas. Lima era allí un caso muy distinto. Al igual que otras ciudades de la costa peruana, era en realidad -como lo ha mostrado muy bien, en forma de una visión literaria, J. M. Arguedas (un destacado escritor y conocedor de la cultura popular andina) en su famoso libro $E l$ zorro de arriba y el zorro de abajo- una máquina gigantesca que transformaba a los indígenas que migraban allí en búsqueda de una existencia mejor, en el lumpenproletariado peruano, que se establecía en los barrios pobres llamados eufemísticamente "pueblos jóvenes". No obstante, los habitantes de esos barrios, aunque seguían manteniendo ciertos rasgos de su cultura "provinciana", campesina (entonces también indigena), no estaban muy interesados en mejorar la suerte de su "mundo étnico de origen", ya que estaban forzados de luchar día a día para sobrevivir en el medio urbano, nuevo y difícil para ellos. Una de las condiciones del éxito de esa estrategia era liberarse lo más pronto posible de la estampa de indianidad y ajustarse al ethos del cholo, es decir un provinciano que vive en la ciudad a pesar de sus rasgos indígenas trata de embutirse en la sociedad urbana-mestiza [Valdivia 2003: 71-109]. 


\section{Las causas del activismo indígena débil}

La cuestiones comentadas arriba parecen indicar ciertas causas internas que pudieran ser relevantes para explicar la debilidad del movimiento indígena en el Perú. Sin embargo, debe causar reflexión el por qué en este país no han sido tomadas las ideas del así llamado "renacimiento indígena" que apareció -a finales de los años 80 del siglo $\mathrm{XX}$, si no antes- en los vecinos Bolivia y Ecuador, que se manifestó mediante la actividad de muchas organizaciones nativas, fuertes movimientos de protesta etnosocial, una lucha eficaz por la restitución de los derechos anteriormente perdidos y la formación de grupos indígenas de presión en los centros del poder. La sorpresa se hace tanto más grande que la atmósfera general de aquella época favorecía los movimientos indígenas reivindicatorios. Era un período cuando tanto en América Latina, como en el mundo entero, se subrayaba cada vez más intensamente la necesidad de respetar los principios de multiculturalidad y plurietnicidad, reconociendo y dando la palabra en el discurso público a los representantes del sector nativo.

Hay que suponer que la no aparición del efecto dominó, lo cual tendría por efecto la toma de las eficaces y espectaculares formas de actividad de los países vecinos, estaba causada por dos factores adicionales: el primero fueron los contactos peruano-ecuatorianos y peruano-bolivianos muy débiles, en el primero de los casos marcados adicionalmente por las tensiones fronterizas, utilizadas por ambos países para los objetivos de su propia propaganda nacionalista. No era un ambiente favorable para contactos más animados entre la población indígena de estos países, sobre todo porque las informaciones sobre lo que ocurría inmediatamente detrás de la frontera eran usualmente empujadas al segundo plano. El segundo factor importante que tenía influencia en la "congelación" (temporal) del movimiento indígena reivindicatorio en el Perú, era la guerra civil contra la guerrilla izquierdista del "Sendero Luminoso" que duró desde los años 80 del siglo XX. Sus consecuencias resultaron catastróficas para el sector indígena, porque los actos militares y el "terror revolucionario" abarcaron más que nada las zonas montañosas, rurales, habitadas por la población indígena. Aunque en el sentido logístico e ideológico el "Sendero Luminoso" estaba orientado principalmente hacia la población rural, es decir indígena, no obstante -debido a su enmarañamiento maoista- muy poco utilizaba en su propaganda los elementos que se refirieran a los contenidos étnicos. Al mismo tiempo, los actos militares, pacificaciones y repre- 
salías brutales estaban asestados principalmente a los indígenas, el hecho que prueban de manera incuestionable los informes de la Comisión de la Verdad y Reconciliación, un órgano que durante los últimos años ha desvelado los inmesurables crímenes cometidos tanto por la guerrilla, como por la fuerzas gubernamentales [Yuyanapaq... 2003].

Durante la guerra, en la provincia, entre la población mayormente indigena, decayó cualquier actividad social, inclusive la que resultara de la tradición del régimen comunitario (comunidad autónoma con un sistema de cargos, funciones sociales intercambiables mediante elecciones), o también de las leyes que determinaran los principios de funcionamiento de la administración local. Cada persona que ocupaba un cargo cualquiera, pudiera estar expuesto a las represalías e incluso perder la vida. En muchos pueblitos no se celebraban las tradicionales fiestas patronales, era dificil completar las autoridades locales, con la caída de la noche los habitantes se parapetaban en casas en temor por sus modestos haberes y vida. En aquellos años difíciles, el objetivo principal era sobrevivir y no buscar a mejorar la suerte de los indígenas mediante la búsqueda de nuevas, más eficaces formas de autoorganización. También en aquel entonces, incrementó considerablemente la migración de la población indígena (campesina) a la ciudades costeñas, a las regiones más seguras, ubicadas lejos de la escena de los actos militares. Todo ello trajo por consecuencia un grave despoblamiento de provincias enteras. Solamente a principio de los años 1990, ya en la fase final de la guerra, en respuesta al terror de los senderistas aparecieron algunas nuevas formas de actividad organizada, como por ejemplo las así llamadas "rondas campesinas", grupos comunitarios de autodefensa, voluntarios, que comenzaron a proteger sus poblados ante la infiltración de los guerrilleros, criminales y saqueadores de ganado [Starn 1991; Kotarska-Śniadecka 2006: 171-179].

Tanto durante la guerra contra el Sendero Luminoso, como también a la vuelta de los siglos, siempre teniendo en la mente la estampa de los tiempos de terror, los peruanos estaban observando con bastante inquietud los acontecimientos que se desarrollaban en el Ecuador y en Bolivia, que demostraban una creciente fuerza de las organizaciones indígenas que exitosamente penetraban los espacios de la actividad estríctamente política. Parece que hubieran sido en gran medida los recuerdos de la guerra civil los que hicieron incrementar de manera importante el temor por una eventual propagación en el Perú del activismo nativo étnico, lo cual pudiera resultar muy peligroso para la siempre delicada estabiliza- 
ción socio-política del país. Por eso, una solución mejor parecía ser la de mantener la dudosa tesis sobre la "inexistencia" de los indígenas en las provincias de la sierra, en espera de que los campesinos sometidos a la desetnización no apelaran a los programas típicamente reivindicatorios y orientados hacia el etnodesarrollo, formulados por las organizaciones indígenas de los países limítrofes.

La presencia de los indígenas en las regiones andinas era en aquel momento un tema delicado, tratado muy prudentemente. Lo mismo se refería también a los círculos científicos, entre los cuales se encontraban los antropológicos que en gran medida ignoraban la problemática del movimiento étnico indigena, argumentando que éste en el Perú no tenía fundamentos, en razón de la ya efectuada transformación de indígenas en campesinos y habitantes del suburbio. Cuando se mira las publicaciones peruanas que atañen las cuestiones de la población rural, se ve claramente que aún en los años 1970 y al comienzo de los 1980, en los títulos de artículos o monografías aparecían de vez en cuando los términos étnicos que identificaban a las sociedades estudiadas como nativas (indígenas). En cambio, en el período ulterior, estos clasificadores desaparecen casi totalmente y son sustituidos por los términos de tipo "población rural", "campesinos", "comuneros" [Degregori (ed.) 2000]. Sólo los investigadores europeos, que llevaban sus investigaciones en los Andes peruanos, seguían empleando los denominadores étnicos "tradicionales" y no pocas veces eran criticados por percibir a los habitantes de las zonas rurales peruanas de manera europocéntrica, es decir viendo en ellos, sin justificación alguna, a los exóticos herederos de la civilización inca.

Es sintomático que en los últimos años del siglo XX y a comienzos del siglo XXI -a pesar de que se haya negado tácitamente la existencia de los indígenas en la sierra peruana- se iba intensificando en el país el debate sobre el pluralismo étnico y sobre la necesidad de adaptar el régimen del Estado a los principios que ordenaban respetar la presencia en su territorio de diferentes grupos etnoculturales. Los debates se desarrollaban no solamente en los gabinetes de los investigadores. Gradualmente, iban abarcando también los círculos gubernamentales y parlamentarios, entonces los medios responsables de una eventual novelización de la constitución y todas las leyes que resultaran de la misma, como también de la puesta en práctica de las normas legales en la vida real de los ciudadanos peruanos.

Vale la pena mencionar en este lugar que en la última constitución, la del año 1993, se habla de las garantías para la diferencia étnica y cultural 
de ciudadanos, del respeto y amparo del Estado sobre la "pluralidad étnica y cultural de la Nación", del derecho a mantener la diferencia lingüística y de la posibilidad de establecer la educación en las lenguas étnicas [Barié 2000: 475-476]. Estas constataciones bastante lacónicas, bastante distantes de las garantías que les dan a los indígenas las constituciones de Colombia, Ecuador o Bolivia, no han frenado la discusión que se está desarrollando en el Perú sobre la teoría y práctica de la "interculturalidad". Igual que en todo América del Sur, se ha abandonado allí el término "multiculturalidad" -el más popular en Europa- y no solamente porque los programas que resulten del mismo han fracasado en el Viejo Continente, sin haber llevado a la integración de los inmigrantes. Los desiderata de multiculturalidad elaborados en los paises pluralistas, formados en el proceso de grandes movimientos inmigratorios (Canadá, Australia), han sido considerados además no compatibles con la realidad peruana. En consecuencia, se emprendió un esfuerzo intelectual con la finalidad de llenar con un contenido bien concreto el lema de "interculturalidad" como un eventual programa para la construcción de una nueva sociedad peruana. Haciendo caso omiso de las diferencias en la interpretación del témino de "interculturalidad", visibles en diferentes escuelas latinoamericanas y corrientes del pensamiento socio-político, podemos notar que se pone el énfasis ante todo en los aspectos de las relaciones interétnicas, del intercambio de los contenidos culturales, de la construcción de entendimiento, de la creación de una atmósfera de respeto para la diferencia, de tolerancia para los modelos alternativos de cultura. Dicho de otra manera, la "interculturalidad" es tratada como un postulado de construcción de una totalidad coherente, aunque diversificada culturalmente, basada en los principios del pluralismo democrático. De acuerdo a esto, la constitución debería garantizar a cada grupo étnico y cultural la posibilidad de mantener su identidad y los derechos que de ella resulten, pero al mismo tiempo debería favorecer la formación de una nación-estado, representada por varias comunidades cooperando entre sí, donde cada una estaría equipada de un bagaje un poco diferente de experiencias y modelos culturales. Son lemas que hoy se inscriben perfectamente en los esfuerzos que tienden a construir una democrática sociedad cívica, que llenaría las divisiones y prejuicios después de los años de la guerra civil y régimen autoritario de Fujimori. Los mismos son acordes también con las tendencias cada vez más nítidas a combatir indicios de racismo, siempre presentes en la vida cotidiana 
y que dificultan la integración tanto de los indígenas, como afroperuanos [Fuller (ed.) 2002].

No obstante, en la práctica, en el debate sobre la interculturalidad, quedó callada o ausente la la población de origen indígena de las zonas de la sierra y ciudades de la costa. Si ya se mencionaba aquel grupo, era en el contexto de los debates sobre las ventajas de introducir la educación intercultural en las regiones donde las lenguas étnicas (quechua y aymara) siguen siendo vivas y utilizadas a diario (provincias en el sur del Perú: Puno, Cusco, Ayacucho, Abancay, Huancavelica). Se hablaba bastante de los afroperuanos o de los descendientes de los inmigrantes del Japón o China, sin embargo, el mayor interés han despertado los "verdaderos" indígenas, es decir los de la Amazonía llamados oficialmente "nativos" (su número total asciende a 240 mil personas aproximadamente, es decir menos de 1\% de toda la población del país) [Chirinos Rivera 2001: 45-46].

El haber concentrado la atención en este segmento de la población nativa ha sido fundado, según parece, por lo menos en dos razones. La primera es el hecho que aunque los nativos amazónicos son poco numerosos $y$ viven en pequeños grupos dispersos, ocupan territorios muy extensos que en la actualidad son áreas naturales de expansión interna de los peruanos, tanto colonizadora como exploradora, debido a la riqueza de las zonas selváticas en recursos naturales (madera, gas, petróleo). Entonces, el problema estratégico es llevar una política étnica que conciliara los contradictorios a esta tendencia intereses de los nativos que viven allí y defienden sus tierras ante la invasión de la "civilización" y de la economía del país que se está desarrollando, buscando al mismo tiempo nuevas fuentes de energía y nuevos terrenos de cultivo y cria. En esta situación, un elemento adicional que hay que tomar en consideración es la opinión internacional que a menudo toma forma de protestas abiertas contra la práctica de no respetar el derecho de la población nativa a controlar sus propias tierras y también contra la evidente violación de los principios de la protección de naturaleza.

La segunda razón que favorece la libertad de discusión y la actividad a favor de los pueblos nativos de la Amazonía, es de otra índole. A saber, los nativos amazónicos, debido a su posición geográfica marginal, su gran dispersión y el bajo número de población, no son amenaza alguna para la integridad del país. Tampoco son un potencial elemento revolucionario que pudiera llevar a una desestabilización socio-política del país a escala que sin duda alguna sería posible si fuera el caso de la población 
indígena de las regiones andinas (como lo han demostrado los acontecimientos de los últimos años en Bolivia y Ecuador). Por eso mismo también, teniendo por objetivo implementar los principios de interculturalismo, es muy cómoda la estrategia de concentrar la atención en esos grupos pequeños, desarrollar programas de ayuda a su favor, introducir regulaciones legales que les permitieran conservar su propia identidad en las condiciones de los procesos de etnodesarrollo. De esta manera se puede enseñar al mundo y a la sociedad nacional que el Estado peruano no descuida las cuestiones indígenas y trata de asegurar a los pueblos nativos las dignas condiciones de existencia.

\section{Primeras formas del activismo indígena}

Los nativos amazónicos peruanos supieron utilizar las circunstancias favorables (al igual que sus hermanos del Ecuador, Bolivia, Colombia o Brasil) para organizarse de manera eficiente. Han creado toda una red de diferentes organizaciones étnicas, comenzando por el nivel local, a través del departamental, hasta el nacional, e incluso hasta el macroregional que abarca todo el territorio amazónico que forma parte de varios paises. Un ejemplo es allí la Coordinadora Indígena de la Cuenca Amazónica (COICA). Dos asociaciones más importantes y más destacadas de los nativos amazónicos del territorio peruano son la Confederación de Nacionalidades de Amazonía Peruana (CONAP) y la Asociación Interétnica de Desarrollo de la Selva Peruana (AIDESEP) que tienen mucho mérito en el fortalecimiento de la posición legal de los nativos y en la lucha por la defensa de sus intereses, entre otros la protección de los territorios nativos ante la amenaza de ser invadidos. Gracias a los animados contactos con las organizaciones no gubernamentales (ONG), estas dos principales federaciones que coordinan la actividad de las asociaciones regionales, supieron alcanzar las metas trazadas y atraer la atención del gobierno y de la sociedad peruana, como también de la opinión internacional, a los problemas particularmente importantes en lo que atañe la conservación de la identidad por los nativos amazónicos (educación intercultural, protección de salud, autonomía territorial, respeto de la tradición y del derecho consuetudinario).

En este fondo la actividad organizacional de los indígenas de la sierra, arbitrariamente considerados campesinos sólo distinguibles por los rasgos 
regionales (etnográficos) de su cultura, no parece imponente. En las zonas de la sierra actuaban ante todo las organizaciones clasistas y sindicalistas cuyos programas agrarios estaban dirigidos principalmente hacia las cuestiones económicas y sociales, sin realizar aspectos étnicos o culturales. Destacaban entre ellas dos estructuras: la Confederación Campesina del Perú (CCP) y la Confederación Nacional Agraria (CNA) que, sin embargo, después de los años de la guerra civil llevada en las zonas rurales, ambas han perdido su dinamismo e influencia política.

La consciencia de la enorme debilidad del movimiento indígena andino (comparado con el de los países limítrofes) hizo que a finales de los años 1990 aparecieron iniciativas con tendencia a crear, desde arriba, asociaciones indígenas de carácter étnico. Lo interesante es que por regla general eran iniciativas externas, es decir no-indígenas, divulgadas en el sector indígena por los políticos, intelectuales y activistas sociales que venían principalmente de los círculos cusqueños. Empero, los analistas limeños en cambios sociales tomaban con una gran desaprobación las sugerencias de "aportar" las ideas étnicas al mundo campesino y de crear así las condiciones indispensables para el "renacimiento indígena". Usualmente, estos "experimentos", que consistían en convocar encuentros, de diferente índole, de personajes importantes para el movimiento indígena, eran considerados actos utópicos -desprovistos de apoyo social- de un grupo reducido de intelectuales románticos de inclinación indigenista, que ignoraban la evidente especificidad del proceso integracionista de formación de la nación, construyendo a nuestra vista una comunidad unida de todos los peruanos.

Tomando en consideración el simbolismo particular de la antigua capital inca, como también la alta saturación del sur del país por la población que conservaba elementos básicos de su cultura indígena, la mayoría de los primeros encuentros, cumbres y conferencias indígenas era convocada en Cusco o en sus alrededores (Ollantaytambo, Machu Picchu). Ya en 1997 fue organizado el Primer Congreso de Derechos Humanos y Pueblos Indigenas cuyo resultado fue la declaración que anunciaba la creación de un foro fijo de debates y trabajos de todos los pueblos y grupos nativos peruanos, con la finalidad de elaborar la estrategía única de actividad a favor de mejorar su suerte. De esta manera, nació la idea de la Conferencia Permanente de los Pueblos Indígenas del Perú (COPPIP) que durante los años ulteriores, a pesar de la división interna en dos corrientes recíprocamente conflictivas, desempeñaba un papel importante en el pro- 
ceso de "renacimiento" del movimiento indigena en el Perú [Alfaro Rotundo 2005].

Dos años más tarde (1999), también en Cusco y en Pisaq -un pueblo cercano, conocido por las ruinas incaicas muy bien preservadas- fue convocado el Primer Encuentro de los Pueblos Quechua de América, es decir una conferencia típicamente internacional que tenía que estrechar la cooperación y el intercambio de experiencias entre las organizaciones y pueblos quechuas de toda la zona andina. En ese histórico encuentro panquechua participaron, al lado de los delegados peruanos, también los representantes del Ecuador, Bolivia y Argentina. Uno de los principales lemas del congreso era buscar la "unidad en la diversidad" mediante la autoorganización de la sociedad indigena quechua, partiendo desde el nivel de las comunidades campesinas locales y llegando hasta el nivel que abarcaba todo el territorio antiguo del Tawantinsuyu, en parte siempre habitado por la población indigena que habla el runa simi (quechua) y comparte los valores básicos de la cultura indígena [Declaración... 2005]. Entre los organizadores del encuentro estaban, entre otros, David Ugarte, el antropólogo de Cusco quien tiene mucho mérito en el "despertar" del movimiento indígena, y Rodrigo Montoya Rojas, también antropólogo, a su vez de Lima, el principal vocero y defensor de los derechos indígenas. Este último, comentando posteriormente dicho evento en uno de los principales periódicos nacionales (La República), subrayó con énfasis que no se debería interpretar las iniciativas étnicas en las categorías del tribalismo separatista que pudiera amenazar la integridad del Estado, ya que esas iniciativas eran nada más que un indicio del nuevo hálito de democracia, que después de años de disturbios nacionales incluía también la población indigena [Montoya Rojas 1999].

Otros dos años más tarde, en 2001, fue convocado en Cusco otro encuentro indígena importante, llamado Primer Congreso Extraordinario de los Pueblos Quechuas del Perú, en el que también participaron los representantes indígenas de varias organizaciones extranjeras, mas solamente en calidad de observadores invitados. Era éste el siguiente paso en el camino hacia la consolidación del movimiento indígena peruano de la sierra, aunque el congreso mismo, al igual que los anteriores, no ha encontrado mayor interés de la opinión pública. No obstante, trajo por resultado una solicitud dirigida a las autoridades estatales de introducir en la constitución nacional una modificación fundamental que debería definir al Perú como un "Estado multicultural y plurinacional". Esta formulación 
permitiría abandonar en definitiva el modelo mestizo-criollo del Estado-nación que excluía a los indígenas de la principal corriente de la vida y que a cambio abriría el camino hacia la construcción de un nuevo modelo de comunidad política donde estarian garantizados los puestos para todos los grupos étnicos, etnoraciales y etnoculturales, de acuerdo al cada vez más citado lema que presenta al Perú como a un país de gente de todas las culturas y razas ("todas las sangres") [Montoya Rojas 2001].

Entre otros eventos importantes de este tipo cabe señalar el Segundo Encuentro de Pueblos Quechuas de América, organizado también en Cusco (2005), en gran medida con el apoyo de dos antropólogos ya mencionados: David Ugarte, quien en aquel entonces dirigía el Instituto Nacional de Cultura que representaba el gobierno, y el profesor universitario Flores Ochoa, un destacado conocedor de la cultura andina y un intelectual que abiertamente subraya sus raíces indígenas. Su intención era refortalecer los esfuerzos por la consolidación del movimiento indígena en las regiones montañosas del Perú a través de construir una plataforma de cooperación e intercambio de experiencias entre los líderes indígenas de diferentes países. En este encuentro internacional -uno de varios que tuvieron lugar en todo el continente americano, pero no sin razón convocado en el Perú, donde el movimiento indigena era siempre débil y necesitaba de apoyo solidario, también del exterior- participaron los delegados de Argentina, Chile, Bolivia, Perú, Ecuador, Colombia y México. Les dieron un fuerte apoyo a los "hermanos" peruanos en sus aspiraciones hacia el reconocimiento de la ilimitada presencia de la población indígena en la vida política, cultural, social y económica del país. Se esperaba que gracias al respeto de los principios de plurietnicidad sería posible la definitiva liquidación de barreras y limitaciones que empujaban a los indígenas al margen de la vida, y que las organizaciones que aceptaran ese desafío, aparecerian en el foro nacional como importantes representantes de la población autóctona del Perú y emprenderían acciones adecuadas al tamaño de la población indígena y a sus necesidades reales [Carta... 2005].

No cabe duda que todos estos encuentros cíclicos, aunque en gran medida organizados por inspiración tanto de los representantes no-indígenas como indigenas, aunque de perfil elitista, co-creaban una atmósfera favorable para las nuevas iniciativas nativas, mas orientadas al pensamiento autónomico. Esas conferencias permitían a los representantes de diferentes organizaciones que actuaban en el sector indigena, pero que hasta entonces se dedicaban más a los asuntos sociales, profesionales o ecológi- 
cos que a los cultural-étnicos, llevar a cabo debates comunes sobre asuntos comunes. Su motivo conductor era el discurso étnico que subrayaba la necesidad de unificar los esfuerzos para crear un fuerte bloque de población nativa que pudiera ejercer presión en las autoridades. El segundo adelanto importante de dichos encuentros era iniciar el intercambio de experiencias entre diferentes grupos indígenas, en particular, tomar conocimiento de los logros de las organizaciones ecuatorianas y bolivianas que en la lucha por sus derechos tuvieron un gran éxito. De este modo, el movimiento de los indígenas peruanos recién nacido, ganó la posibilidad de emplear modelos de actividad ya existentes, elaborados por las asociaciones nativas como la CONAIE (Confederación de las Nacionalidades Indígenas del Ecuador) y ECUARUNAI (federación de las organizaciones indígenas de la sierra) del Ecuador o el sindicato de campesinos-indígenas CSUTCB (Confederación Sindical Única de Trabajadores Campesinos de Bolivia) y CONAMAQ (El Consejo Nacional de Ayllus y Markas del Qullasuyu) - federación de las comunidades indígenas aymaras y quechuas de Bolivia.

\section{Los indígenas peruanos y los proyectos políticos de activación del sector popular}

Los encuentros y las conferencias de los líderes indigenas en Cusco, durante los años 1997-2006, preparaban las condiciones para las futuras acciones organizadas de los indígenas peruanos. Sin embargo, paralelamente a este proceso que en realidad comprometía grupos limitados de élites activistas, en el Perú se podia notar la aparición cada vez más visible de elementos indígenas en el discurso político nacional. No se puede menospreciar este fenómeno, aunque presente principalmente en el espacio simbólico, puesto que ha influido de manera significativa en el cambio de percibir a los indigenas en la sociedad peruana moderna, sociedad que hasta entonces vivía en cierta esquizofrenia, de un lado reconociendo las raíces indigenas e incaicas de su país, mas del otro arrojando de su consciencia y de su lengua la presencia de la población nativa.

El momento crucial fueron las elecciones presidenciales de 2000 cuando durante la campaña electoral los campesinos de raíces indígenas se han vuelto el blanco de la propaganda de los partidistas que luchaban por ganarse votos. Fue ante todo Alejandro Toledo quien apelaba al electo- 
rado originalmente indígena y lo hacía tanto durante el período de su lucha por la presidencia como después de haber tomado este cargo (2001-2006). En razón de su origen "campesino" e inconfundible aspecto indigena, rápido se ganó el apodo de "cholo". Para sobrepujar a su predecesor -presidente Fujimori (llamado "chino" debido a sus orígenes japonesas) quien durante su mandato prestaba mucho interés por el desarrollo de la infraestructura de las regiones de la sierra (promoviendo la construcción de carreteras, prestando ayuda a las comunidades campesinas, apoyando las iniciativas locales de desarrollo, etc.) - trataba por todos los medios de presentarse a la población rural como alguien quien había salido del mismo sector, quien tenía una similar experiencia de vida, conocía perfectamente sus problemas diarios, respetaba sus costumbres y-cuando era necesario- hablaba su lengua. Por eso, durante las reuniones con los electores campesinos no pocas veces vestía un poncho y un gorro andino multicolor, se refería abiertamente a la tradición quechua histórica y mítica, sugiriendo entre líneas que se parece en cierto sentido al gran reformador incaico Pachacutec y, al igual que ese destacado soberano de hace siglos atrás, pondría bases para construir un nuevo Perú, un país donde todos -inclusive los indígenas, hasta entonces marginalizadosserían ciudadanos de pleno derecho [Greene 2006].

Fueron justamente estos elementos de propaganda los que hicieron que sobre todo en la prensa europea se escribía a menudo de A. Toledo como de un presidente indígena del Perú lo cual era muy exagerado. Era un político listo quien entendia el espíritu de la época y se daba cuenta de la importancia de los símbolos peruanos (principalmente indígenas) en la activación de la masas. Por eso, no solamente se refería a la cultura popular contemporánea de los indígenas de la sierra, sino que también manipulaba simbología incaica, causando la impresión de que su gobierno sería en cierta medida el regreso al perdido "siglo de oro" de la época del Tawantinsuyu. Una referencia a esta simbología era la marcha de apoyo al presidente Toledo organizada por su partido (Perú Posible) bajo el lema "La marcha de los cuatro suyus". El nombre con el que fue bautizada esa gran peregrinación de los partidarios de Toledo, que venían a la capital de todas las regiones del país, hacía referencia a la división del Tawantinsuyu (Imperio Inca) entre cuatro provincias principales (suyu). Los manifestantes, que provenían de todos los círculos sociales, llevaban las banderas del Tawantinsuyu con el retrato del Inca Pachacutec cuyo rostro era el de $\mathrm{A}$. Toledo. El evento estaba acompañado de la música andina 
y un sinfín de accesorios indígenas de carácter folclórico [Chávez Eslava 2002].

Después de su victoria electoral, A. Toledo seguía explotando la simbología incaica, por ejemplo organizando la ceremonia de ocupar el cargo presidencial en un lugar muy particular para el Perú, a saber en la ruinas de Machu Picchu. Allí, rodeado por los sacerdotes de la religión andina que hacían ofrendas a los apus (dioses de la montaña) y a Pachamama (Madre Tierra), prestó el sermón [Vich 2003: 451-463]. Es obvio que esas manifestaciones no tenían por meta activar directamente a los indígenas. Se trataba más bien de demostrar que las nuevas autoridades representarían por fin-después del período del régimen autoritario de Fujimori- a todos los peruanos y en particular a aquellos que hasta entonces eran excluidos, y perseguidos durante la cruel guerra civil. La simbología utilizada por Toledo tenía que hacer referencia más a la "nueva etnicidad" de todos los peruanos, como una nación sincrética de raíces andinas, que a los indígenas, ausentes hasta la fecha en la escena política, quienes de este modo deberían ser "despiertos" del letargo. No obstante, la aparición en el espacio público (por primera vez desde el gobierno de Velasco Alvarado) de los elementos indígenas acentuados de manera tan fuerte y que manifestaran a todos otra cara etnocultural del Perú, tuvo que ejercer influencia no solamente sobre los que anhelaban un "nuevo patriotismo" de los mestizos. No cabe duda que influyó, y hasta en un grado mayor, en la población indígena que en este ascenso del rango de su propia tradición vio a sí misma y al mundo de sus tradiciones en una luz más provechosa. Creo que fueron acciones de este tipo las que iniciaron el proceso psicológico de salida de los indígenas del complejo de inferioridad impuesto por la situación endocolonial y salida de la trampa etnosocial de estigmatización, y que les permitieron ir descubriendo los valores de su propia cultura como fundamento para construir el "orgullo étnico".

En la obra de manipular los símbolos, al presidente Toledo le ayudaba su esposa Eliane Karp, proveniente de una familia belgo-francesa con raíces judías en Europa del Este, antropóloga y etnolingüista de profesión, quien hablaba bien el quechua, que había conocido a su marido peruano en la norteamericana Universidad de Stanford. Sus intereses profesionales de la época la habían traído al Perú donde, en la región de Cusco, realizaba un estudio de campo entre las comunidades indígenas. Luego, durante años, trabajaba en las organizaciones financieras internacionales e instituciones israelíes. Reapareció en el Perú ya como "primera 
dama", al lado del ex-marido con el que se había casado por segunda vez. Decidió entonces dedicarse nuevamente a la problemática indígena e iniciar una nueva etapa en la política del Estado ante la población nativa, política que tenía que cambiar radicalmente su suerte y llevar a cabo los fundamentales cambios de modernización, unidos sin embargo con la preservación de la identidad etnocultural [Arce Borja 2004; Kotarska-Śniadecka 2006: 273-286].

E. Karp se consideró a sí misma la principal persona del país responsable del proceso de emancipación de los indígenas peruanos y creó con esta finalidad una agenda gubernamental especial para los asuntos indígenas, poniéndose de hecho a su cabeza. Era la Comisión Nacional de las Comunidades Andinas, Amazónicas y Afroperuanas (CONAPA). Desde el comienzo de su existencia, esta institución estaba sometida a duras críticas de varios medios, en parte también de los indígenas, en razón de su carácter propagandista y el modelo paternalista de actuar que consistía en acciones arbitrales, no consultadas con las organizaciones indígenas, dirigidas por E. Karp y por personas nombradas por ella. En realidad, se puede decir que en este caso particular tuvimos que ver no solamente con una iniciativa tomada decididamente desde arriba, sino también con una nueva forma del indigenismo estatal que reactivando el movimiento indígena (entre otros apoyando las iniciativas de los congresos cusqueños), tenía pensado someterlo simultáneamente al control gubernamental. Aprovechando la situación, se promovía la imagen de E. Karp como peruana, aunque solamente "por naturalización" (durante una ceremonia espectacular organizada en Cusco), pero también como lideresa de la nación quien entendía perfectamente a los indígenas, y la esposa del "primer indígena de origen campesino quien había sido elegido presidente del Perú por vía democrática". A pesar del gran ruido de propaganda que acompañaba la creación de CONAPA, esta agenda no era muy visible en la escena socio-política y, al final, bajo el fuego de una crítica muy dura (que concernía también las irregularidades financieras), en 2004 fue disuelta [Hildebrandt Chávez 2007].

No obstante, las consecuencias de la actividad de esta institución resultaron ser bastante significativos, tanto en el sentido positivo como negativo. De un lado, demostró que en el nuevo orden político del Perú contemporáneo ya no se puede construir bases de una sociedad democrática sin la participación de la población indígena que tenía por fin "renacer", rechazar su posición marginal y entrar como un partenaire de 
pleno derecho en la escena de la vida cívica del país. Sin embargo, del otro lado, la actividad de CONAPA ha provocado divisiones bastante profundas en el naciente movimiento indígena que consistían en la aparición de dos orientaciones competitivas. Una de ellas, políticamente más centrista, estaba lista a cooperar con la administración nacional, las organizaciones internacionales y extranjeras (americanas y europeas) que apoyaban económica y logísticamente esas nuevas acciones. La segunda orientación, más cercana al campo de la izquierda, se oponía fuertemente contra ese tipo de enredos, en vista del peligro de perder la auténtica autonomía y temiendo las difíciles de reconocer manipulaciones que amenazarían a todos quienes tuvieran demasiada confianza en las fuerzas del grupo dominante.

\section{La reindianización del Perú}

Todos los acontecimientos comentados arriba, procesos y tendencias, iban creciendo despacio, gradualmente, a veces hasta de manera imperceptible. No obstante, anunciaban los cambios venideros, fundamentales, tanto en lo que concernía la actitud del Estado frente a los asuntos indígenas, a las relaciones de la sociedad peruana con la población nativa, e igualmente las transformaciones de consciencia de los indígenas mismos quienes descubrían de nuevo su identidad casi perdida y buscaban su propio espacio en la realidad multicultural peruana. Un papel relevante desempeñó también la popularidad étnica, cada vez mayor, del discurso reivindicativo - una herramienta eficaz en la lucha por lograr salirse de las posiciones socialmente marginalizadas, vencer la opresión de varios siglos y nivelar los mecanismos de exclusión. Esta herramienta hizo que a comienzos del siglo XXI, también en la zona andina, las viejas organizaciones clasistas, usualmente de carácter sindicalista, comenzaron poco a poco a transformarse en las estructuras de nuevo tipo que acentuaban muy fuertemente sus objetivos étnicos.

Los fenómenos parecidos no son en esta parte del mundo nada extraordinario. Lo mismo pasó mucho antes en el Ecuador, procesos similares tocaron también a Bolivia. En ambos estos países, a partir de los años 1990, las organizaciones que representaban los intereses sociales y profesionales de los campesinos (indígenas en gran mayoría) han comenzado a expresarse en voz alta en el interés de los pobladores 
indígenas andinos, y luego, ampliando sus programas de "renacimiento" de los nativos, incluyeron en ellos el postulado de construir sociedades nacionales multiculturales lo cual tenía que garantizar a todos los indígenas ( $\mathrm{y}$ a otras minorías, por ejemplo de origen africano o asiático) un lugar justo en el nuevo sistema estatal [Massal 2005; Enrique López, Regalsky (eds.) 2005; Participación... 2005]. En definitiva, los mismos procesos tuvieron lugar también en el Perú, país que hasta hacía poco sorprendía a todos los analistas por carecer de un movimiento indígena organizado en las zonas de la sierra, sólo que allí el activismo indígena apareció mucho más tarde que en otras regiones de América indígena. En la parte final de este artículo, quisiera concentrar mi atención en algunos de los síntomas de "regreso" de los indígenas en la escena política y social del Perú, sin embargo, lo voy a hacer sin desarrollar ampliamente el tema, ya que su análisis escrupuloso exige una observación corriente de los fenómenos, que siempre quedan in statu nascendi.

Dichos procesos se hicieron visibles en particular en los años 2005-2006, en dos esferas fundamentales: de formación de las nuevas estructuras organizacionales que representaban los intereses de la población indígena, y de desarrollo de las iniciativas proindígenas en los círculos no nativos. Hoy día, ambas esas corrientes, donde la primera es de carácter decididamente indianista (es decir resulta de la actividad de los indígenas mismos) y la otra toca las tradiciones del indigenismo (es decir iniciativas a favor de los indígenas realizadas por el medio externo para ellos), se entrelazan fuertemente y son interdependientes. Para un observador exterior, el carácter de estas relaciones es muy a menudo no del todo visible, mientras que para un investigador resulta muchas veces difícil de identificar, en particular cuando se toma en cuenta las cuestiones financieras, ideológicas, organizativas, legales, políticas y las del apoyo a los movimientos indígenas por parte de los grupos de presión. Sin embargo, no cabe duda que sin diferentes acciones de ayuda, el activismo indígena no hubiera sido capaz de desempeñar un papel significativo y duradero en la vida social y política de los países de América Latina, entonces Perú incluido.

Al lado de las dos principales organizaciones sindicales campesinas mencionadas arriba (CCP y CNA), que actúan en la zona andina y que participando cada vez con más ganas en diferentes reuniones indígenas han tratado de manifestar su compromiso en los asuntos de la defensa de la identidad indígena, apareció una tercera organización, por su genesis 
igualmente distante de la ideología indianista, pero que va ampliando con mucha velocidad el campo de actividad y pone un fuerte acento en las ambiciones de ganarse la posición del principal representante del sector indígena de la sierra, de igual importancia por lo menos que la que tiene la federación AIDESEP en las regiones amazónicas.

Se trata de la Confederación Nacional de Comunidades del Perú Afectadas por la Minería (CONACAMI), constituida en 1999, entonces una organización que originalmente agrupaba las asociaciones locales campesinas de las comunidades afectadas por las consecuencias negativas de la actividad industrial de las compañías extractoras. La Confederación se dedicaba principalmente a luchar contra las empresas mineras que impunemente contaminaban el medio ambiente rural (agua, suelo, aire), empeorando las condiciones de vida y de trabajo de los campesinos andinos, ya lo suficientemente difíciles. Su actividad estaba dirigida hacia frenar la expansión fuera de control de dichas empresas, hacia arrancar una mejor protección del entorno de las minas y obtener recompensas justas por la tierras y la salud perdidas, y por los terrenos degradados.

No obstante, los últimos dos años, CONACAMI cambió totalmente de carácter y trata de hacerse el principal representante del sector indígena de toda la sierra peruana. A nuestra vista, se está transformando en una fuerza social, de amplias ambiciones políticas que piensa realizar tanto en la escena nacional como en el espacio internacional panandino y panindigena [Montoya Rojas 2006]. Junto con la mencionada arriba federación de las organizaciones de los indígenas amazónicos (AIDESEP), ha creado una macrorepresentación de los indígenas peruanos: la Coordinadora de los Pueblos Indígenas del Perú (COPIP). Este comité atrajo la atención de la opinión pública cuando en 2004, en la ciudad de Huancavelica, organizó la Primera Cumbre Indígena en la que participaron los representantes de 180 comunidades nativas de diferentes regiones del Perú, y donde llegaron también los invitados de los países andinos limítrofes. No cabe duda que el encuentro fue un intento de activar a los sectores indígenas básicos y fortalecer la plataforma (creada sobre todo "desde arriba") para el acuerdo indígena mediante la creación de un mecanismo de consultación y comunicación entre las élites, que encabezaban las organizaciones peruanas a nivel nacional, y los líderes locales elegidos en las elecciones directas en las comunidades y los pueblitos andinos.

Sin embargo, cabe destacar que el elemento característico de la vida social y política de los indígenas andinos (no solamente en el Perú) son 
permanentes problemas con construir una estructura organizacional nacional, estable, uniforme y aceptada por todos, que tuviera calidad de una representación real y fidedigna de toda la diversificada red de comunidades indigenas locales, asociacio- nes, grupos regionales y pueblos nativos. Es obvio que sobrepasar las diferencias naturales de intereses de tantas agrupaciones es una tarea muy difícil, sin embargo, el principal factor desestabilizador son ahí las ambiciones de liderato demostrados por los nuevos dirigentes nativos quienes de muy mala gana se someten a la disciplina y son capaces de competir violentemente entre sí, aniquilando los acuerdos, poniéndose a la cabeza de fracciones y creando nuevas organizaciones.

En el Perú, este fenómeno apareció con una gran fuerza ya en la fase inicial, cuando se estaban formando las nuevas organizaciones étnicas. Se manifestó en particular con la división de la COPIP en dos fracciones (que utilizaban siglas casi idénticas) que se enfrentaban, acusándose recíprocamente de no tener el carácter auténticamente indígena. En consecuencia, en 2006, de una de las fracciones (denominada Conferencia Permanente de los Pueblos Indígenas del Perú - COPPIP) fue constituida una nueva organización indigena general llamada Confederación de $\mathrm{Na}$ cionalidades Indígenas del Perú (CONAIP), con fundamentos decididamente más fuertes sentados en las organizaciones "básicas" del sector indigena (comunidades), apoyada por las "rondas campesinas" (vigilantes comunitarios) y por los movimientos de cocaleros (cultivadores de coca que luchan por legalizar sus cultivos). De esta manera, ya desde los principios de la creación y consolidación del movimiento indígena organizado en el Perú, aparecieron dos centros competitivos entre los que uno (Coordinadora de los Pueblos Indígenas del Perú - COPIP) goza de un visible apoyo de las autoridades y organizaciones internacionales (como: Oxfam, Fondo Indígena, o Fundación Adenauer), mientras que el otro (CONAIP) parece tener el carácter más "popular", que hace referencia a las experiencias "revolucionario-populistas" de las organizaciones indígenas de Bolivia [Lucero, García Sarah 2006].

En 2006 tuvo lugar otro acontecimiento importante: fue creada la primera organización indígena panandina, que se trazaba como meta coordinar estratégicamente la lucha por los derechos de los indígenas en la zona incluida en todos los países de esta parte del continente sudamericano, partiendo de Colombia, a través del Ecuador, Perú, Bolivia, y terminando en Chile y Argentina. En cuanto a la parte peruana, esta asociación que se 
llama Coordinadora Andina de Organizaciones Indígenas (CAOI), ha sido nombrada con un fuerte apoyo de la CONACAMI. La ambición de los líderes de las organizaciones que forman parte de la CAOI era crear una alternativa indígena para la Comunidad Andina de Naciones que lleva años funcionando, que agrupa los gobiernos de los países citados y trata de dar forma al curso de los asuntos en esta parte de América del Sur.

Tal como hemos dicho arriba, el segundo plano importante para las relaciones interétnicas en el Perú que se están modificando, lo determina la influencia de las instituciones no indígenas sobre los pueblos nativos. Obviamente, en esta escena importante, el actor es siempre el Estado, independientemente del tipo de la política étnica que lleve. Después de los años de ignorar las cuestiones indígenas, también en este campo pueden ser observadas tendencias positivas que -aunque siempre débilesseñalan cambios, graduales y seguramente forzados, en la orientación vigente hasta la fecha.

Uno de los indicios de la nueva actitud pueden ser algunas decisiones tomadas por el Perú, junto con los demás países de la Comunidad Andina, vinculadas directamente con la cuestión indígena. Sobre todo, cabe mencionar aquí la declaración de Machu Picchu del año 2001 donde el gobierno del Perú se comprometía a prestar su apoyo a todas las iniciativas que tiendan hacia la "plena incorporación de la población indígena en la vida económica, social y política". En base a esto, un año más tarde, en Urubamba cerca de Cusco, fue convocado un gran encuentro de los representantes de gobiernos, organizaciones indigenas, instituciones de protección de los derechos humanos, y expertos de los asuntos étnicos, durante el cual fue constituida la Mesa Indígena de la Comunidad Andina. En su intención tenía que ser una especializada plataforma de debates de trabajo dedicados únicamente a los problemas de vida de la población indígena, que coordinaría la actividad de las instituciones gubernamentales de los países de la Comunidad Andina con las organizaciones indigenas más importantes, con la finalidad de promover el etnodesarrollo de este sector de la población nativa y hacer incrementar su participación en el proceso de la integración andina [Fortaleciendo... 2003]. A pesar de todo, éste y muchos otros encuentros en los niveles más altos de poder, aunque su significado queda más que nada simbólico, abren a la población indígena el camino legal para la ejecución cada vez más eficaz de sus derechos y para la implantación de las reformas indispensables.

A los objetivos parecidos sirve en el Perú una agenda gubernamental 
especializada, en el rango del ministerio, constituida todavía a finales del gobiemo del presidente A. Toledo (2004) en el lugar de la comprometida CONAPA, manejada por su esposa E. Karp. Esta nueva institución, que se llama Instituto Nacional de los Pueblos Andinos, Amazónicos y Afroperuanos (INDEPA), tiene que funcionar en un estilo diferente, reemplazando la anterior actitud paternalista y los modos arbitrales de tomar decisiones, por consultas permanentes y cooperación con las organizaciones indígenas y sus líderes. Su primera y más importante tarea parece ser el vencer la profunda desconfianza de los medios indígenas hacia esa "nueva" agenda, para que la misma pueda ser considerada, de un lado, como un partenaire real de las asociaciones indígenas, y del otro, como coordinadora de las organizaciones de apoyo (ONG) funcionando correctamente.

Hoy en día, el papel de las organizaciones de apoyo es enorme (además, no solamente en los países andinos). En realidad, algunas de ellas funcionan con el mandato de los gobiernos de los países europeos (p.ej. Holanda, Gran Bretaña o España), otras en nombre de las organizaciones internacionales (p.ej. Banco Mundial, Organización de los Países Americanos, Organización Mundial de la Salud), otras más son de carácter más independiente y encuentran apoyo en las fundaciones (usualmente extranjeras) religiosas, sociales, sindicales, educativas, etc. Sin la ayuda de éstas -económica, logística y de otro tipo- la mayoría de las organizaciones indígenas no podría funcionar de manera lo suficientemente eficaz para poder convocar congresos, pagar juristas y expertos, mantener oficinas, editar publicaciones, organizar talleres y cursillos, enviar a sus representantes a diferentes encuentros importantes, nacionales e internacionales, ni tampoco realizar muchos programas que tiendan a mejorar la situación sanitaria, económica, educativa o ambiental. La actividad de las ONG es por una parte recibida con aprobación, mas por la otra es denegada por un grupo hoy día bastante numeroso de críticos (que se sitúan tanto del lado del Estado, como también del lado de los círculos izquierdistas) quienes dicen que el movimiento indígena basado en esta ayuda es en realidad poco auténtico y sometido a manipulaciones. Estas últimas, es decir las ONG, tienen que ser un indicio del "imperialismo cultural" europeo y norteamericano que divulgue entre los indígenas los "modelos de actividad que les sean ajenos" e incita a los indígenas a "rebelarse" contra la administración local y el gobierno central, o -todo el contrarioque pacifica su espíritu revolucionario mediante la modernización parcial 
de su vida y acostumbrándolos a las reglas de la "pseudodemocrática sociedad de mercado".

Observando imparcialmente los fundamentales supuestos de las organizaciones de apoyo, se puede llegar a la conclusión de que uno de los objetivos -no verbalizados directamente- de muchas de ellas, en particular aquellas más fuertes y más influyentes (como Fundación Ford, Fundación Adenauer, Oxfam de Inglaterra, o IBIS de Dinamarca), es no solamente ayudar materialmente a los indígenas, sino también invertir en las élites nativas en vía de formación, levantar bases de la autonomía indígena local y de las estructuras organizacionales representativas, promover el etnodesarrollo, apoyar la lucha por la protección legal de los indígenas, etc. Todo esto tiene que acelerar el proceso de la ciudadanización de los indigenas y facilitarles el funcionamiento dentro del marco de la sociedad democrática, y por ende asegurar la estabilización social en la región andina, lo cual -debido a la gran falta de igualdad económica y a la existencia de grandes sectores de pobreza- era considerado siempre un terreno de potenciales revoluciones, rebeliones, movimientos guerrilleros, como también un terreno de regímenes autoritarios, constituidos usualmente para pacificar el caos y la violencia izquierdistas.

Hace poco, en el discurso de los activistas de las ONG reapareció el término "indígena" referido a la población rural de las regiones de la sierra. Es éste, el que poco a poco va sustituyendo los términos oficiales de "campesino" y "comunero", forzados por las autoridades peruanas desde el año 1969. Cada vez más se emplea hoy el término "campesinos-indígenas", separando a este grupo de todos los "campesinos" en general donde muchos son campesinos mestizos. De esta manera, la actual red terminológica, basada en la división de clases y de profesiones, sufre el proceso de erosión y se observa el regreso hacia la terminología étnica. Además, se observa que también en las ciudades viven indígenas a los que, en vez de llamarlos simplemente "cholos", se comenzó a determinar como "indígenas urbanos". En cambio, refiriéndose a toda la población nativa, entonces a los indígenas andinos y amazónicos, campesinos y urbanos, se empezó a emplear el cada vez más popular término "pueblos originarios" (pueblos nativos, autóctonos), prestado de Bolivia, pero que hace referencia también al vocabulario étnico norteamericano que exige llamar a aquellos indígenas con el término first peoples ("pueblos primeros", es decir los más antiguos en el continente). Estos juegos semánticos son por supuesto nada más que la señal de un gran cambio en la política 
social, que demuestra la sustitución progresiva del discurso clasista (comprometido por los gobiernos populistas y agrupaciones izquierdistas) por un nuevo tipo de lenguaje "correcto políticamente", ensamblado en la concepción de un estado democrático pluriétnico y una sociedad multicultural.

Un campo de actividad muy importante para las organizaciones de apoyo es también la educación (concienciación) de la joven generación indígena, entonces su preparación a la vida y actividad en las nuevas condiciones democráticas y pluralistas de la sociedad cívica. Teniéndolo por objetivo, se van realizando, ya desde algunos años, programas experimentales que consisten en ofrecer becas a los jóvenes indígenas y en activar especializadas pistas educativas para esta categoría de alumnado, como también en ofrecerles un apoyo de autoria que suprima diferencias que existan entre el nivel de educación en las escuelas de la provincia y las de las grandes ciudades, y por fin, en iniciar las acciones cuya meta es fortalecer la identidad de los jóvenes indígenas expuesta a una acelerada asimilación en el ambiente urbano. Este tipo de actividad es emprendido exitosamente en la universidad de Cusco, en el marco del programa "Hatun Nan", financiado por la Fundación Ford, en el que participan activamente los antropólogos locales [Boletín... 2006]. Proyectos similares - dirigidos a los estudiantes indígenas y que tenía por objetivo formar a las futuras élites indigenas que, habiendo terminado sus estudios universitarios, no estarian absorbidas por la principal corriente de la sociedad mestiza- son realizados también en los centros universitarios de Lima (Universidad Mayor de San Marcos), Ayacucho, Puno y Pucallpa, facilitando de esta manera la educación de los alumnos de los sectores quechuas, aymaras y amazónicos.

\section{Conclusiones finales}

El panorama de formación progresiva del movimiento indigena peruano, que hemos presentado arriba -desde las formas muy poco avanzadas hasta las cada vez más activas y visibles en el foro nacional e internacionaldemuestra que es un fenómeno que se desarrolla de manera similar a la observada en muchos otros países donde el número de población indígena es elevado. Sólo que es bastante atrasado en el tiempo, debido a la especificidad de la situación socio-política del Perú en la segunda mitad del sig- 
lo XX. Imposible entonces buscar justificativo alguno para la tesis de que la sociedad peruana no estuviere incluida en los procesos del activismo indígena (característicos para Bolivia y Ecuador), sobre todo teniendo en cuenta el alto grado de integración de la población de raíces indígenas con la principal corriente de la nación y los bastante avanzados cambios de identidad de esta parte de la población que, pareciera, haya borrado de su memoria el recuerdo de sus raíces étnicas.

Durante los últimos años, entre la población de las zonas montañosas, comenzaron a construirse de manera muy dinámica las estructuras básicas del movimiento indigena organizado. Había por lo menos tres vías de crear esta red organizacional, a saber: (1) la de arriba, realizada por los líderes indígenas que tenían todas las características de los así llamados "indígenas profesionales" (personas que desde hace años estaban participando en diferentes comisiones, gremios para los asuntos de la población nativa, y que gozaban de un limitado apoyo de las estructuras ubicadas más "abajo"), (2) la transformacional, que consistía en transformar las organizaciones ya existentes (clasistas, profesionales, reivindicativas o ecológicas) -que actuaban en las zonas rurales y en el nombre de la población campesina- en las estructuras que hoy sobreponen claramente las metas étnicas sobre las que eran al comienzo sus prioridades sociales, económicas o ambientales, (3) la "de abajo", entonces iniciada por el activo de las sociedades indígenas "de base" que actuaban en el marco de autonomías locales, rondas campesinas, círculos de animación rural de mujeres, cooperativas agrícolas, pastoriles, artesanales, grupos estudiantiles, etc. Es obvio que cada una de estas vías tiene sus ventajas y sus desventajas, no obstante, llevan a la misma meta común: arar la consciencia étnica dormida, activar diferentes medios indígenas y poco a poco consolidar las estructuras organizacionales, indispensables para crear en el Perú un fuerte grupo indígena de presión, que pudiera realmente influir en el curso de los asuntos en el país y en la región. En este campo queda todavía muchísimo por hacer lo que pueden probar las experiencias y el alto nivel de organización de los indígenas bolivianos y ecuatorianos.

Otro fenómeno interesante son las relaciones recíprocas entre las organizaciones de los indígenas andinos y amazónicos, y el cambio de su significado. Al igual que sucedía antes en el Ecuador, las organizaciones de los indigenas peruanos de las regiones selváticas bajas eran al principio unas de las que funcionaban mejor y luchaban eficazmente en el foro nacional e internacional por el derecho a los territorios ocupados. No 
obstante, desde cuando en la escena vienen entrando las organizaciones de los indígenas de la sierra, cada vez más fuertes y que representen un porcentaje significativo de toda la población del país, son éstas las que comienzan a desempeñar el papel principal como partenaire potencial en las negociaciones con las autoridades, como también en la iniciativas panindigenas realizadas en la arena internacional.

Un rasgo específico del activismo indígena peruano es no solamente el hecho de que éste se está formando a partir de una verdadera "nada", sino también el hecho de que le toca actuar en un ambiente decididamente más estable y más democrático que aquel que se observa en el Ecuador o Bolivia. En ambos estos países las organizaciones indígenas son un participante importante del juego político cotidiano, que a menudo desestabiliza seriamente la vida económica del país debido a su participación en bloqueos de carreteras, huelgas generales, manifestaciones revolucionarias o alianzas que lleven a cambios de gobiernos. En este fondo, el desarrollo de las organizaciones peruanas y las estrategias de su actividad merecen una atención continua, porque sólo observando el desarrollo de acontecimientos se podrá constatar si las fuertes representaciones de la población indígena ejercerán una influencia estabilizadora sobre toda la sociedad y el estado, o si - todo el contrario- llevarán a confrontaciones y crisis, copiando los modelos rebeldes de sus vecinos.

Otra tendencia más que vale la pena destacar es la muy rápida incorporación de las recién creadas estructuras indígenas del Perú en el movimiento indígena panandino, como también en los acuerdos panindígenas continentales. Es algo que de un lado prueba que los lideres de este movimiento quieren salir rápido de la fase de aislamiento y ser un importante actor de los encuentros internacionales y, del otro, expresa la tendencia de líderes a utilizar las ya existentes asociaciones supranacionales para ganar el indispensable apoyo y aprovechar los ya confirmados modelos de actividad.

De momento, las ambiciones políticas de los nuevos movimientos indígenas en el Perú son limitadas, puesto que -ante la permanente amenaza del mal de fraccionamientos- toda su energía está concentrada en las acciones de consolidación. No obstante, no cabe duda que cuando se logre combatir este problema, y las condiciones internas lo permitan, los indigenas peruanos, al igual que los indígenas de los países limítrofes, querrán entrar en la escena política: tanto a nivel de autonomías -provinciales y departamentales-, como en el ámbito de la administración 
central y del poder repúblicano. Las experiencias anteriores en este campo son todavía muy modestas, igualmente la preparación mental del resto de la sociedad para un tal "retorno" de los indígenas siempre deja mucho por desear, como lo ha probado de forma ostentosa la aparición en el parlamento de una diputada indígena vistiendo su traje étnico (regional), quien de vez en cuando se expresa explícitamente en el idioma quechua, el hecho que ha causado inmediatamente fuertes réplicas de los círculos desfavorables a tales experimentos "multiculturales" [Perú... 2006].

Las aspiraciones de los indígenas peruanos a la reforma de la legislación actual, y sobre todo de la constitución, y por ende al cambio de situación de la población indígena en los sectores clave de su vida, las expresó rudamente uno de los líderes nativos de la Coordinadora Andina, y a la vez presidente de CONACAMI - Miguel Palacín Quispe. A saber, constató que los indígenas de ninguna manera deberían ser percibidos como un grupo subversivo que amenace la seguridad social del país y su integridad territorial. Lo dijo con estas palabras: "somos un peligro para... la democracia monocultural... y somos una luz para el ejercicio de una democracia multicultural". Luego dijo también que los indigenas quieren participar activamente en la vida pública del Estado, pero que tiene que ser "un estado plurinacional institucionalizado e incorporando a todos" [Miguel Palacín Quispe... 2006]. El desarrollo de los acontecimientos demostrará indudablemente si estos postulados ganan una aprobación más amplia y quedan incorporados en la vida, para que la población autóctona del Perú pudiera sentir que vive en un país que no solamente es tierra de sus admirables ancestros, sino también el país de ellos; para que pudiera gozar plenamente de sus derechos cívicos, saliendo de la miseria y marginalización social; $y$, por fin, para que pudiera -modernizándose-conservar su identidad indígena basada en los valores de su propia cultura.

Traducido por: Iwona Stoińska-Kairska

\section{BIBLIOGRAFÍA}

ALFARO ROTONDO S., 2005, Nación, política e identidad en el movimiento indigena peruano, Revista RIDEI (Pontificia Universidad Católica del Perú, Lima), no. 4; www.pucp.edu.pe/invest/ ridei/boletin_marzo2005.

ARCE BORJA L., 2004, Primera dama del Perú. Eliane Karp: pasado y presente, El Diaro Internacional (01.04.2004); www.volairenet.org (consultado 21.03.2007).

BARIÉ C. G., 2000, Pueblos indigenas y derechos constitucionales en América Latina: un panorama, México: Ed. Banco Mundial. 
Boletin... 2006, Boletin Hatun Nan (Universidad Nacional San Antonio Abad, Cusco), vol. 2, no. 3.

CADENA M. de la, 1999, Indigenous Mestizos. The Politics of Race and Culture in Cusco, Peru 1919-1991, Durham: Duke University Press.

Carta... 2005, Carta abierta a los presidentes de la Comunidad Sudamericana de Naciones. 5 de agosto del 2005, en: Los pueblos indigenas ante el mundo global. II Encuentro de Pueblos Quechuas de América, Cusco, agosto del 2005, Cusco: Instituto Nacional de Cultura, pp. 15-18.

CHÁVEZ ESLAVA A. W., 2002, Movimientos étnicos y construcción de identidades en el Perú y Ecuador (II Encuentro Metropolitano de Jóvenes Investigadores Sociales, UNMSM, mayo 2002), Lima (ponencia accesible en la base "ridei" - www.pucp.edu.pe/invest/ridei).

CHIRIF A., C. MORA, 1977, Atlas de comunidades nativas, Lima: Ed. Sistema Nacional de Movilización Social (SINAMOS).

CHIRINOS RIVERA A., 2001, Atlas lingüistico del Perú, Lima-Cusco: Ministerio de Educación; Centro Bartolomé de las Casas.

CHIRINOS RIVERA A., M. ZEGARRA LEYVA, 2004, Educación indigena en el Perú, Lima: Ministerio de Educación.

Declaración... 2005, Declaración del Primer Encuentro de los Pueblos Quechuas de América, en: Los pueblos indigenas ante el mundo global. II encuentro de pueblos Quechuas de América, Cusco, agosto del 2005, Cusco: Instituto Nacional de Cultura, pp. 219-221.

DEGREGORI C. I. (red.), 2000, No hay pais más diverso. Compendio de antropologia peruana, Lima: Instituto de Estudios Peruanos.

ENRIQUE LÓPEZ L., P. Regalsky (eds.), 2005, Movimientos indigenas y Estado en Bolivia, La Paz: Ed. Plural.

Fortaleciendo... 2003, Fortaleciendo capacidades y espacios de diálogo entre las organizaciones indigenas de los paises andinos, Lima: Ed. Banco Mundial.

FULLER N. (ed.), 2002, Interculturalidad y política. Desafios y posibilidades, Lima: Pontificia Universidad Católica del Perú; Universidad del Pacífico; Instituto de Estudios Peruanos.

GREENE Sh., 2006, Getting over the Andes. The Geo-Eco-Politics of Indigenous Movements in Peru's 21 st Century Inca Empire, Journal of Latin American Studies, vol. 38, pp. 327-354; www.indiana.edu (consultado 21.03.2007).

HILDEBRANDT CHÁVEZ C., 2007, ¿ De qué sirve la CONAPA?, www.agenciaperu.com (23.03.2007).

IGUINIZ J. (ed.), 1989, La cuestión rural en el Perú, Lima: Pontificia Universidad Católica del Perú.

KOTARSKA-SNNIADECKA M., 2006, Być kobietq w Peru (1980-2005), Warszawa: CESLA UW.

LIZCANO FERNÁNDEZ F., 2005, Composición étnica de las tres áreas culturales del continente americano al comienzo del siglo XXI, Convergencia (Toluca, México), Año 12, núm. 38, pp. 185-232.

LUCERO J. A., M. E. GARCIA SARAH, 2006, Reflexiones sobre la autenticidad indigena, los movimientos sociales y el trabajo de campo en el Perú contemporáneo, www.voltairenet.org/article144504 (consultado 16.02.2007).

MASSAL J., 2005, Les mouvements indiens en Equateur. Mobilisations protestataires et démocratie, Paris: Karthala.

MEENTZEN A., 2005, Indigena und Politik im Andenraum: Peru, KAS-Auslandsinformationen, no. 1, pp. 30-56.

Miguel Palacin Quispe... 2006, Miguel Palacin Quispe elegido Coordinador General. Al concluir el congreso fundacional de la Coordinadora Andina de Organizaciones Indigenas; www.minkandina.org/article (consultado 16.08.2006).

MONTOYA ROJAS R., 1999, La necesidad de un proyecto político quechua en el Perú, La República (Lima), 28.11.1999.

MONTOYA ROJAS R., 2001, Congreso de los pueblos Quechuas, La República (Lima), 18.11.2001. 
MONTOYA ROJAS R., 2006, Un acontecimiento político. Nace una Coordinadora Andina de Organizaciones Indigenas de Ecuador, Bolivia y Perú; www.minkandina.org/article (consultado 16.08.2006).

Participación... 2005, Participación politica, democracia y movimientos indigenas en los Andes, Lima: Institut Français d’Études Andines - Fundación PIEB - Embajada de Francia.

Perú... 2006, Perú: "Sé que va a haber discriminación". Entrevista a Hilaria Supa Huamán, www. servindi.org/archivo/2006/868 (consultado 16.02.2007).

POSERN-ZIELIŃSKI A., 1985, Kraina Inkarri. Szkice etnologiczne o Peru, Wrocław: Ossolineum.

POSERN-ZIELIŃSKI A., 2005, Między indygenizmem a indianizmem. Andyjscy Indianie na drodze etnorozwoju, Poznań: Wyd. UAM.

POSERN-ZIELIŃSKI A., 2006, Wpływ migracji na przemiany społeczno-kulturowe ludności tubylczej Ameryki Andyjskiej. Przypadek Ekwadoru, en: Migracje i Spoteczeństwo, t. 11 (Migracje i Kultura), Warszawa: Wyd. IH PAN, pp. 76-92.

QUISPE QUISPE A., 2003, Indios contra indios, La Paz: Ed. Nuevo Siglo.

STARN O., 1991, "Con los llanques todo barro" Reflexiones sobre rondas campesinas, protesta rural y mevos movimientos sociales, Lima: Instituto de Estudios Peruanos.

STEFANONI P., H. DO ALTO, E. Morales, 2006, De la coca al palacio. Una oportunidad para la izquierda indigena, La Paz: Ed. Malatesta.

VALDIVIA N., 2003, Etnicidad, pobreza y exclusión social: la situación de los inmigrantes indigenas en las ciudades de Cusco y Lima, en: J. Uquillas, T. Carrasco, M. Rees (comp.), Exclusión social y estrategias de vida de los indigenas en Perú, México y Ecuador, Quito: Ed. Banco Mundial, pp. 28-129.

VICH C., 2003, 29 de julio de 2001: Toledo en el Cusco o Pachacutec en el mercado global, en: M. Hamann, S. López Maquina (eds.), Batallas por la memoria. Antagonismos de la promesa peruana, Lima: Pontificia Universidad Católica del Perú, pp. 451-463.

WOOD D., 2005, De sabor nacional. El impacto de la cultura popular en el Perú, Lima: Instituto de Estudios Peruanos.

Yuyanapaq... 2003, Yuyanapaq. Para recordar. Relato visual del conflicto armado en el Perú, 1980-2000 , Lima: Ed. Comisión de la Verdad y Reconciliación. 